ISSN 1112-9867

\title{
RECENT PROGRESS OF NANOREFRIGERANT DEVELOPMENT: A REVIEW
}

\author{
M. Z. A. Rehim and M. R. M. Nawi ${ }^{*}$ \\ Faculty of Mechanical Engineering, Universiti Teknologi MARA, 40450 Shah Alam, \\ Selangor, Malaysia
}

Published online: 17 October 2017

\begin{abstract}
Nan refrigerant is produced by blending nanoparticle in the refrigerant base. The purpose of nanoparticle in refrigerant base is to enhance the heat transfer performance, thus beneficial to any cooling application. This paper presents of a review of recent progress of nanorefrigerant development and its characterisation. Results of previous experiment of nanorefrigerant mixture which aim to enhance the heat transfer coefficient (HTC) are presented. Moreover, enhancement of heat transfer coefficient based on concentration, size of nanoparticle and type of nanoparticle used in experiment studies are also presented. In general, with the increment of nanoparticle concentration the viscosity is increased and instantaneous enhanced the thermos-physical properties such as thermal conductivity.
\end{abstract}

Keywords: nanorefrigerant; heat transfer enhancement; refrigerant base.

Author Correspondence, e-mail:muhad@salam.uitm.edu.my

doi: http://dx.doi.org/10.4314/jfas.v9i5s.20 


\section{INTRODUCTION}

Beginning uses of refrigerant in refrigerator, air conditioning system. Recently, electronic cooling system like computer also have been used refrigerant in their cooling system. There is 2 type of matter state in refrigerant, it is liquid and gasses. Industrial of refrigerant usually use gasses refrigerant to supply for their consumer like refrigerator or air conditioning in transportation. In early air conditioning in car using R-134A to produce cool air inside car. R-134A still use in industrial of refrigeration system, but the uses of R-134A had been banned because of the effect of chlorofluorocarbon (CFC) to environment. The global effect of CFC such as Green House phenomenon, decimation of ozone and etc. In order to protect environmental, at 2011 all transportation restricted to use the HFC refrigerant. MAC directive is banned all the refrigerant from Global Warming Potential (GWP) factor more than 150 [1].

Nanorefrigerant is called when the presence of nanoparticle is blended well in refrigerant. There is several influence presence of nanoparticle in refrigerant, it is enhancement of thermal conductivity, increment of viscosity, friction coefficient and wear rate can be decrease if nanoparticle is dispersed in base fluid such as lubricant [1]. Nanorefrigerant have possibility to enhance the heat transfer performance in several applications such as boiling, heat exchanger, air conditioning and etc can be reachable. There are some studies proved that the presence of nanoparticle in refrigerant can enhance the heat transfer performance [2-6].

The dispersion of nanoparticle in refrigerant called nanorefrigerant have been studied by many researchers. The objective of this paper is to present review on the development of nanorefrigerants for several types of refrigerant bases and its performance of heat transfer.

\section{INNOVATION OF NANOREFRIGERANT STUDIES AND ITS APPLICATION}

In early 2013, there 3 type of refrigerant have been use as nanorefrigerant. In [2] using HFE7000 engineering fluid classified as refrigerant in liquid state, the nanoparticle used is $\mathrm{Al}_{2} \mathrm{O}_{3}$. In [3] is use refrigerant is $\mathrm{R} 141 \mathrm{~b}$ blended with $\mathrm{Al}_{2} \mathrm{O}_{3}$, in[4] also using $\mathrm{R} 141 \mathrm{~b}$ with $\delta-\mathrm{Al}_{2} \mathrm{O}_{3}$. In [5] using R-134a blended with $\mathrm{Al}_{2} \mathrm{O}_{3}$. Performance of heat transfer every study give drastically or a little different between each other. Table 3 shown the performance of heat transfer in their application system.

Earlier research of nanofluids in boiling heat transfer application, usually nanoparticle 
blended with water/deionized water such as shown in Table 4. In nanofluids with water base, there is so many types of nanoparticle have been used from metallic, non-metallic, tube shape and etc.

However, refrigerant fluid is another type of fluid can give a more impact possibility in nanofluids technology in term enhancing heat transfer performance. In refrigerant, there is two type of refrigerant as in Fig. 1. It shows that there is pure and mixture refrigerant already developed by industry to enhance thermal properties and lower the effect in environmental effect such as GWP, ODP and etc.

Table 1.Summary of nanorefrigerant and its thermal performance

\begin{tabular}{lccc}
\hline Reference & Refrigerant & $\begin{array}{c}\text { Nano } \\
\text { Particles }\end{array}$ & Enhancement and Deterioration of Studies
\end{tabular}

There is surfactant use in nanorefrigerant to make mixtures more stable. Application used is pool and flow boiling on horizontal wire at different

[2] $\quad \mathrm{HFE7000} \quad \mathrm{Al}_{2} \mathrm{O}_{3}$ gravity level. Size of nanoparticle used is $27 \mathrm{~nm}$. The deterioration of heat transfer performance is nucleation of bubble on the heater surface and the enhancement is the heat transfer coefficient increased.

Thermal conductivity enhanced with increasing of volume concentration. Enhancement of volume concentration is more aggressive than enhancement with temperature. Properties of [3] $\mathrm{R}-141 \mathrm{~b} \quad \mathrm{Al}_{2} \mathrm{O}_{3} \quad$ viscosity is incline with increasing particle volume fraction, however increment is decrease with increasing of temperature. Enhancement of thermal conductivity is lower than increment of viscosity.

Surfactant SDBS had been used in [4] $\quad \mathrm{R}-141 \mathrm{~b} \quad \delta-\mathrm{Al}_{2} \mathrm{O}_{3}$ nanorefrigerant to make nanorefrigerant more stable. At $0.001 \mathrm{vol} \%$, presence of surfactant is decrease the performance of heat transfer. At 
$0.01 \mathrm{vol} \%$ and $0.1 \mathrm{vol} \%$ presence of surfactant is enhanced the heat transfer performance because of reduction sedimentation of nanoparticles. The heat transfer performance is increase with increasing volume concentration.

Properties of thermal conductivity enhanced with increasing of volume fraction of nanoparticle and temperature. Enhancement of volume concentration more effected than temperature increment of thermal conductivity properties. Increment of volume concentration causes of increment viscosity, then if same concentration applied to other type of refrigerant give an opposition of viscosity effect. Significantly, heat transfer performance of nanorefrigerant is enhanced with increasing of concentration.

The nanorefrigerant at $0.01,0.03$ and $0.05 \mathrm{vol} \%$ concentration is investigated. Cylindrical copper tube is had chosen as heat surface to nucleate [6] $\quad \mathrm{R}-141 \mathrm{~b} \quad \mathrm{TiO}_{2}$ boiling. Heat transfer performance is decreased with increment of volume concentration. The heat transfer coefficient at high pressure between $400 \mathrm{kPa}-500 \mathrm{kPa}$ with excess temperature, the value almost same.

The volume concentration was investigated is $0.1,0.2$ and $0.3 \mathrm{wt} \%$. The result of thermal $\mathrm{Cu}, \mathrm{CuO}$,

[7] $\quad \mathrm{R}-141 \mathrm{~b} \quad \mathrm{Al}$ and performance is maximum heat transfer coefficient enhanced from 17 to $25 \%$, average HTC enhanced from 3 to $20 \%$ and maximum enhancement $\mathrm{R}-141 \mathrm{~b} / \mathrm{Cu}$ is enhanced by $25 \%$. 


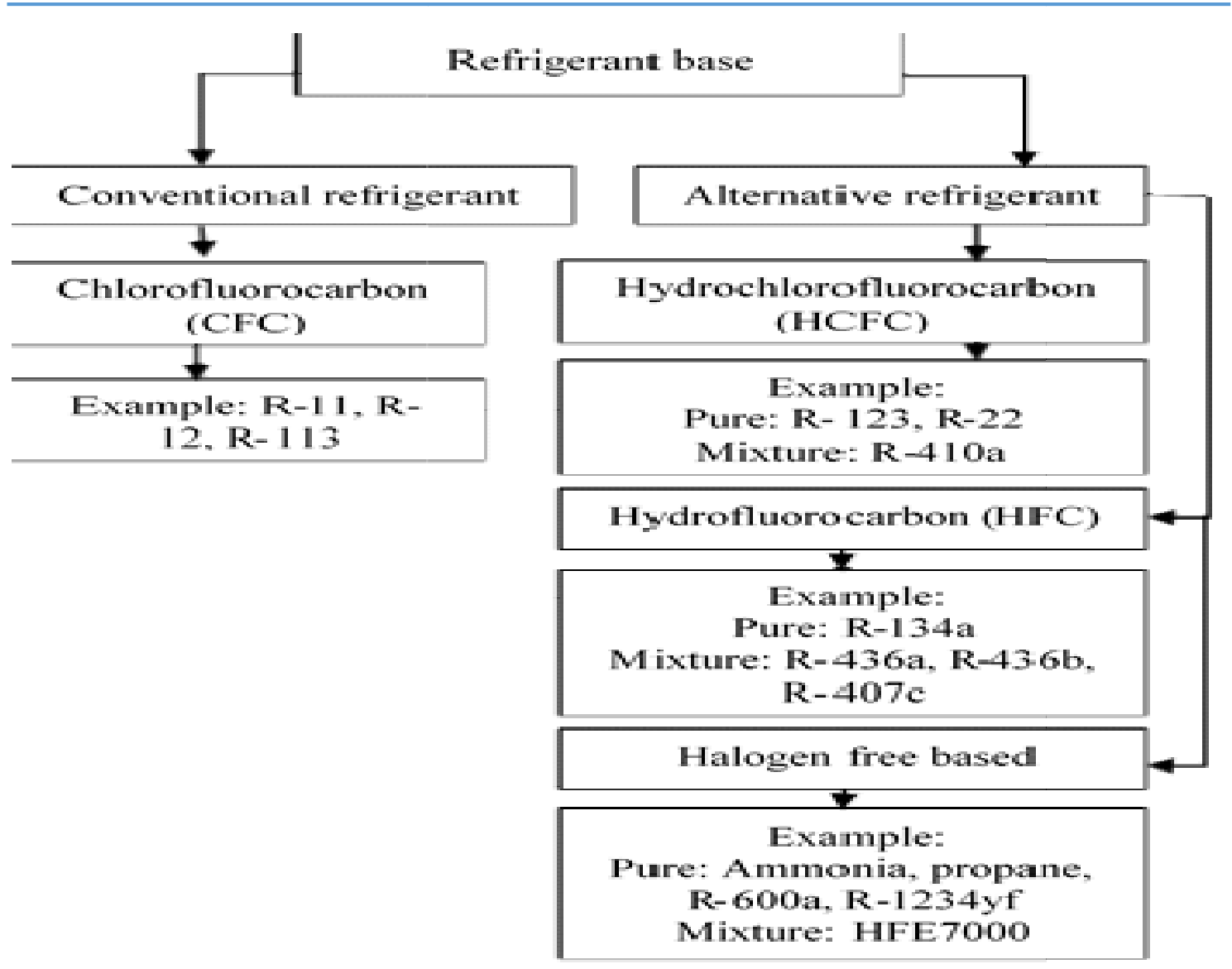

Fig.1.Division of refrigerant base [1]

There still more researcher investigate of CFC refrigerant with nanoparticle to convert nanorefrigerant in factor of handling of refrigerant, inflammable gas and disposal management of refrigerant.

\section{CLASSIFICATION REFRIGERANT BASE}

Based Montreal protocol had been banned CFC refrigerant commercial used as said by reference [1], they divided 2 division classification of refrigerant as shown in Fig. 1. Classification 1 is conventional refrigerant with had ingredient of chlorine and second classification is alternative refrigerant to reduced amount of chlorine in refrigerant.

\subsection{Conventional Refrigerant}

Since 90s-year refrigerant CFC base already banned because of effect to the environmental. Table 2 shows that experimental studies using CFC base refrigerant. In 2009, there are several researchers used conventional refrigerant such as [8] used R-11 with nanoparticle of titanium for size $21 \mathrm{~nm}$ diameter. At $0.1 \mathrm{vol} \%$ concentration give a 1.4 times efficiency than base 
refrigerant performance on heat pipe applications. Next, in[9] is used refrigerant R-113 with $\mathrm{CuO}$ nanoparticle. The investigation of experiment more about frictional pressure drop on flow boiling application. The frictional pressure drop is increased with enhancement of mass fraction nanoparticles. In heat transfer performance in reference [10] proved that, the heat transfer coefficient enhanced compare than refrigerant base (R-113).

Comparison between nanofluid with water base and nanorefrigerant with spherical nanoparticle and nanorefrigerant with Carbon Nano Tube (CNT) made by [9] used R-113 refrigerant. The heat transfer performance proves that, thermal conductivity of nanorefrigerant of CNT is much higher than spherical nanorefrigerant and nanofluids of water base. The hypothesis of nanorefrigerant CNT is the thinner diameter of CNT nanoparticle, the bigger enhancement of thermal conductivity of nanorefrigerant. Next, comparison of type nanoparticle between copper,aluminum, nickel, copper oxide and aluminum oxide with R-113 refrigerant is experimented by [12]. The result proved that, thermal conductivity of nanorefrigerant is enormously enhanced with increasing of volume fraction nanoparticle. The type of nanoparticle is not too different with other type of nanoparticle in nanorefrigerant with same of volume concentration [10]. The factor of agglomerate and assemblage of nanoparticle in nanofluids is highlighted by [12] is main element to enhanced thermal conductivity in nanofluids.

In 2010, nanorefrigerant experiment still continues with uses of conventional refrigerant by [13]. The type of refrigerant used is R-113 in oil mixture with various size of CNT in application of nucleation pool boiling. The result of experiment proved that heat transfer coefficient (HTC) is enhanced by maximum of $61 \%$ under experiment test condition. The thinner of outer diameter and more increasing of length of CNT nanoparticle causes increasing enhancement HTC. At same dimension size of CNT, the enhancement of nanorefrigerant is increased with increment of CNTs mass fraction in CNT nanolubricant[13]. Next investigation nanorefrigerant of R113 and the oil is VG68 with diamond nanoparticle [14]. The result proved, the HTC of R-113 oil mixture with diamond nanoparticle is higher than R-113 oil mixture with maximum of $63.4 \%$. Hypothesis from experiment is enhancement of HTC is increased by increment of nanoparticles concentration in the nanoparticles/oil suspension and decline with the increment of nanoparticles/oil suspension concentration. 


\subsection{Alternative Refrigerant}

The experimental studies of nanorefrigerant using alternative refrigerant start in year of 2009 by [6]. Summaries of experimental result shows in Table 1.

Table 2.Summaries of conventional refrigerant experiment investigation of thermal properties

\begin{tabular}{|c|c|c|}
\hline Reference & $\begin{array}{c}\text { Nano } \\
\text { Refrigerant }\end{array}$ & Thermal Properties \\
\hline [8] & $\mathrm{R}-11 / \mathrm{Ti}$ & Efficiency 1.4 times greater than refrigerant base. \\
\hline [9] & $\mathrm{R}-113 / \mathrm{CuO}$ & $\begin{array}{l}\text { The maximum enhancement of frictional pressure drop is } \\
\text { about } 20.8 \% \text {. }\end{array}$ \\
\hline$[10]$ & $\mathrm{R}-113 / \mathrm{CuO}$ & The maximum enhancement of HTC is about $29.7 \%$. \\
\hline$[11]$ & R-113/CNT & $\begin{array}{l}\text { The percentage of thermal conductivity enhancement from } \\
43 \text { to } 104 \% \text { with different of volume concentration. }\end{array}$ \\
\hline [12] & $\begin{array}{l}\mathrm{Cu}, \mathrm{Al}, \mathrm{Ni}, \mathrm{CuO} \\
\text { and } \mathrm{Al}_{2} \mathrm{O}_{3}\end{array}$ & $\begin{array}{l}\text { Thermal conductivity is greatly enhanced with increment of } \\
\text { nanoparticle volume fraction. The overall maximum } \\
\text { deviation of result compare with other nanofluids from } 5 \text { to } \\
11 \%\end{array}$ \\
\hline [13] & $\begin{array}{l}\mathrm{R}-113 / \mathrm{CNT} \text { oil } \\
\text { mixture }\end{array}$ & The enhancement of HTC up to $61 \%$. \\
\hline$[14]$ & $\begin{array}{l}\text { R-113/ Diamond } \\
\text { with VG68 oil } \\
\text { mixture }\end{array}$ & The maximum enhancement of HTC from 53.4 to $63.4 \%$. \\
\hline
\end{tabular}

\section{PREPARATION AND MEASUREMENT TECHNIQUE FOR NANO REFRIGERANT}

\subsection{Preparation Method}

In [2] using method preparation for nanorefrigerantof $\mathrm{HFE} 7000 / \mathrm{Al}_{2} \mathrm{O}_{3}$, the mixture is sonicated in ultrasonic bath for 8 hours, Triton X114 added as surfactant to mixture more stable. The mixture is filtered by $200 \mathrm{~nm}$ paper to removed agglomerated nanoparticle because of after sonicated process, still have bulky nanoparticle in mixture. Filtration of mixture causes the concentration of mixture is diluted from concentration of preparation. Some of the mixture is dry to measure weight of nanoparticle after filtration process. To prepare other 
concentration of nanorefrigerant, dilution technique is used by adding base fluid in the mixture.

Next, in[3] preparation of $\mathrm{R}-141 \mathrm{~b} / \mathrm{Al}_{2} \mathrm{O}_{3}$ nanorefrigerant. The refrigerant and nanoparticle were mixed by using orbital incubator shaker for 24 hours at $240 \mathrm{rpm}$, during process temperature was under controlled at $15^{\circ} \mathrm{C}$ to prevent refrigerant evaporate. In [4] applied ultrasonic vibration for 10 hours and sodium dodecyl benzene sulphonate (SDBS) added as surfactant to make nanorefrigerant more stable or well blended in refrigerant. In [12], used method preparation for nanorefrigerant of $\mathrm{R}-141 \mathrm{~b} / \mathrm{TiO}_{2}$. Refrigerant mixed with nanoparticle using ultrasonic vibration for 6 hours to make mixture well blended with nanoparticle.

Furthermore, in [7] using method preparation of Cu-R141b, Al-R141b, A12O3-R141b and $\mathrm{CuO}-\mathrm{R} 141 \mathrm{~b}$ nanorefrigerant. The nanoparticle directly mixed to measured amount of refrigerant based on required of concentration studies. The mixture has been shaken with ultrasonic shaker for 30 minutes. Span80 used as surface dispersant in nanorefrigerant. In [13] used method preparation of nanorefrigerant for R-113/CNT oil mixture. First, CNT nanoparticle is weight measured based on required concentration. CNT nanoparticle mixed directly with VG68 lubricant to make nanolubricant. Then, CNT/VG68 nanolubricant mixed with R-113, lastly, all mixture applied to the ultrasonic vibration to make nanorefrigerant in oil mixture well blended.

Hence, in [14] method preparation of nanorefrigerant for R-113 /diamond nanoparticle in oil mixture is same method with [13]. Next, in[10] method preparation for nanorefrigerant of $\mathrm{R}-113 / \mathrm{CuO}$. The basic method is the refrigerant and nanoparticle need to be measured weight based on calculation concentration, then nanoparticle and refrigerant mixed together to apply sonication by ultrasonic processor for 30 minutes. In [11] used same method of preparation for nanorefrigerant of R-113/CNT with [10]. Last but not least, in[12] used method preparation of nanorefrigerant of R-113 with various of nanoparticle, it is copper, aluminium, nickel, copper oxide and aluminium oxide is same with [10-11].

\subsection{Measurement Thermos-Physical Properties Technique}

In [2] measure the thermos-physical and colloidal properties of nanorefrigerant for the colloid density, vapour density, viscosity, surface tension, specific heat capacity and the thermal conductivity is determined. The stability of nanorefrigerant determined by dispersion of 
nanoparticle in refrigerant, dynamic light scattering (DLS) is used by confirming of scattering size nanoparticle in refrigerant. The viscosity of nanorefigerant is determined by using Ubbelohde capillary tube, the viscosity is measured the kinematic viscosity. The specific heat is determined by using Differential Scanning Calorimeter (DSC), the DSC is calculated required amount of heat to be applied to the nanorefrigerant between mixture and reference data. The surface tension of nanorefrigerant is determined by using capillary method. The thermal conductivity is made by measuring thermal diffusivity.

There is 2 thermo-physical properties measured by [3], it is thermal conductivity and viscosity. Thermal conductivity $(\mathrm{W} / \mathrm{mK})$ properties by using KD2 Pro thermal properties analyser (Decagon, USA) and dynamic viscosity properties by using LVDV series (LVDV II, LVDV III, and LVDV III Ultra Programmable) viscometers. The accuracy measurement of KD2 Pro thermal properties analyser (Decagon, USA) from range of 0.02 to $2.00(\mathrm{~W} / \mathrm{mK}$ ). The range accuracy of the thermal properties analyser is about $\pm 5 \%$. The equipment for measured viscosity is suitable for low viscous fluid, the range of accuracy from range from 1.0 to $6,000,000 \mathrm{mPa} . \mathrm{s}$ by using the UL Adapter as an accessory with the viscometer. The measurement of nanorefrigerant base R-134a by [5] also using same method with [3].

Next, measurement of thermal conductivity by [11]. The equipment to measure thermal conductivity is thermal constants analyser produced by Hot Disk Company. The sensor uses in equipment is transient plane source (TPS) method. The theory for measure the thermal conductivity by using the Fourier Law of heat conduction. The theory almost same with the transient hot wire (THW). The procedure to measure the thermal conductivity of nanorefrigerant, first to manipulate the nanorefrigerant temperature by immersed the vessel in thermal bath. Second, the vessel must be in vertical position to easier the analyser to measure the thermal conductivity. Every temperature is taken 3 times to make sure the measurement is accurate. In [12] is using same method of measurement of thermal conductivity from [11].

The summaries of preparation and measurement of thermos-physical properties for nanorefrigerant is shown at Table 3.

Table 3. Summaries of method of preparation and measurement

\begin{tabular}{clcc}
\hline Reference & Nanorefrigerant & Preparation & Measurement \\
\hline$[2]$ & $\mathrm{HFE} 7000 / \mathrm{Al}_{2} \mathrm{O}_{3}$ & 8 hours sonication & Kinematic viscosity
\end{tabular}


KD2 Pro thermal properties analyser

$[3,5] \quad \mathrm{R}-141 \mathrm{~b} / \mathrm{Al}_{2} \mathrm{O}_{3}$
24 hour shakers under $15^{\circ} \mathrm{C}$ temperature controlled
(Decagon, USA) and LVDV series (LVDV II, LVDV III, and LVDV III

Ultra Programmable) viscometers

Sonication 10 hours, SDBS added as surfactant

Sonication 6 hours $\mathrm{Cu}-\mathrm{R} 141 \mathrm{~b}$,

Al-R141b, A12O3-R141b, Ultrasonic 30 minutes, Span 80 added as surfactant Nucleation pool boiling Nucleation pool boiling and $\mathrm{CuO}-\mathrm{R} 141 \mathrm{~b}$
$\mathrm{R} 113 / \mathrm{CuO}$
Ultrasonic processor 30 minutes analyzer produced by Hot

\section{R-113/CNT oil} mixture

R-113/Diamond oil mixture

\section{Ultrasonic processor 30 minutes}

Ultrasonic vibrator

Ultrasonic vibrator
Flow boiling analysis

Thermal constants Disk Company

$$
\begin{aligned}
& \text { Internal copper thread } \\
& \text { tube }
\end{aligned}
$$

Nucleation pool boiling

Nucleation pool boiling

Table 4. Water base nanofluids for boiling heat transfer applications

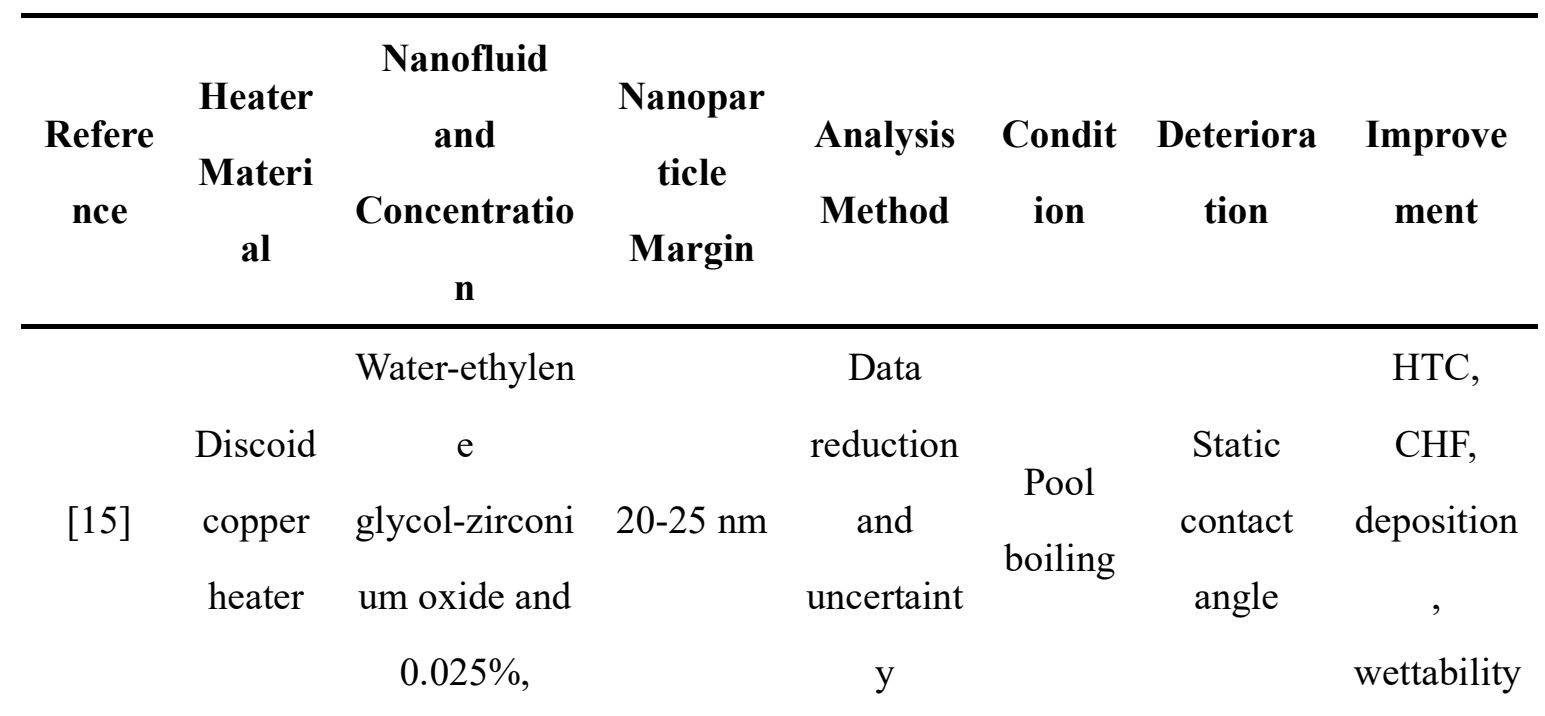




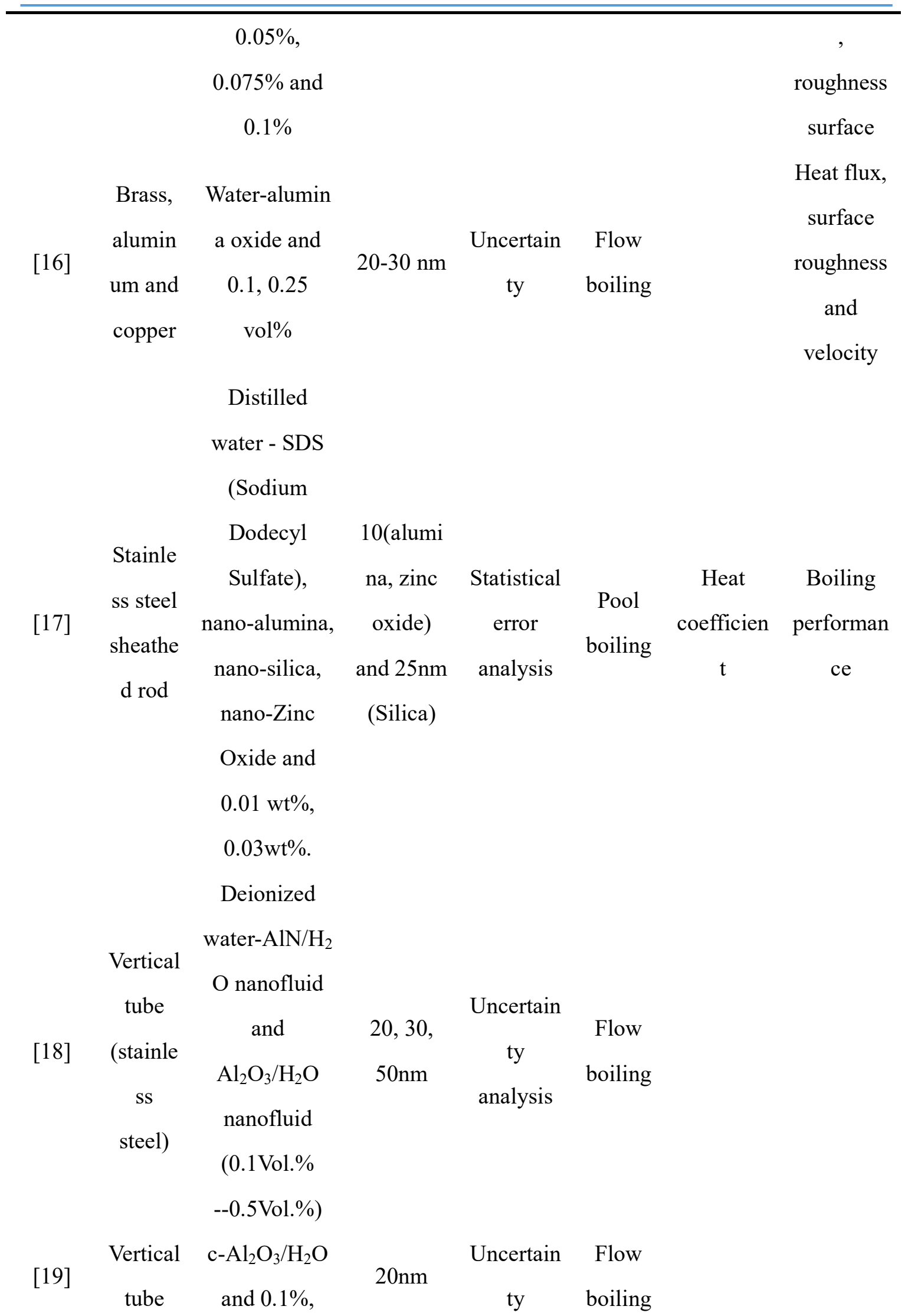




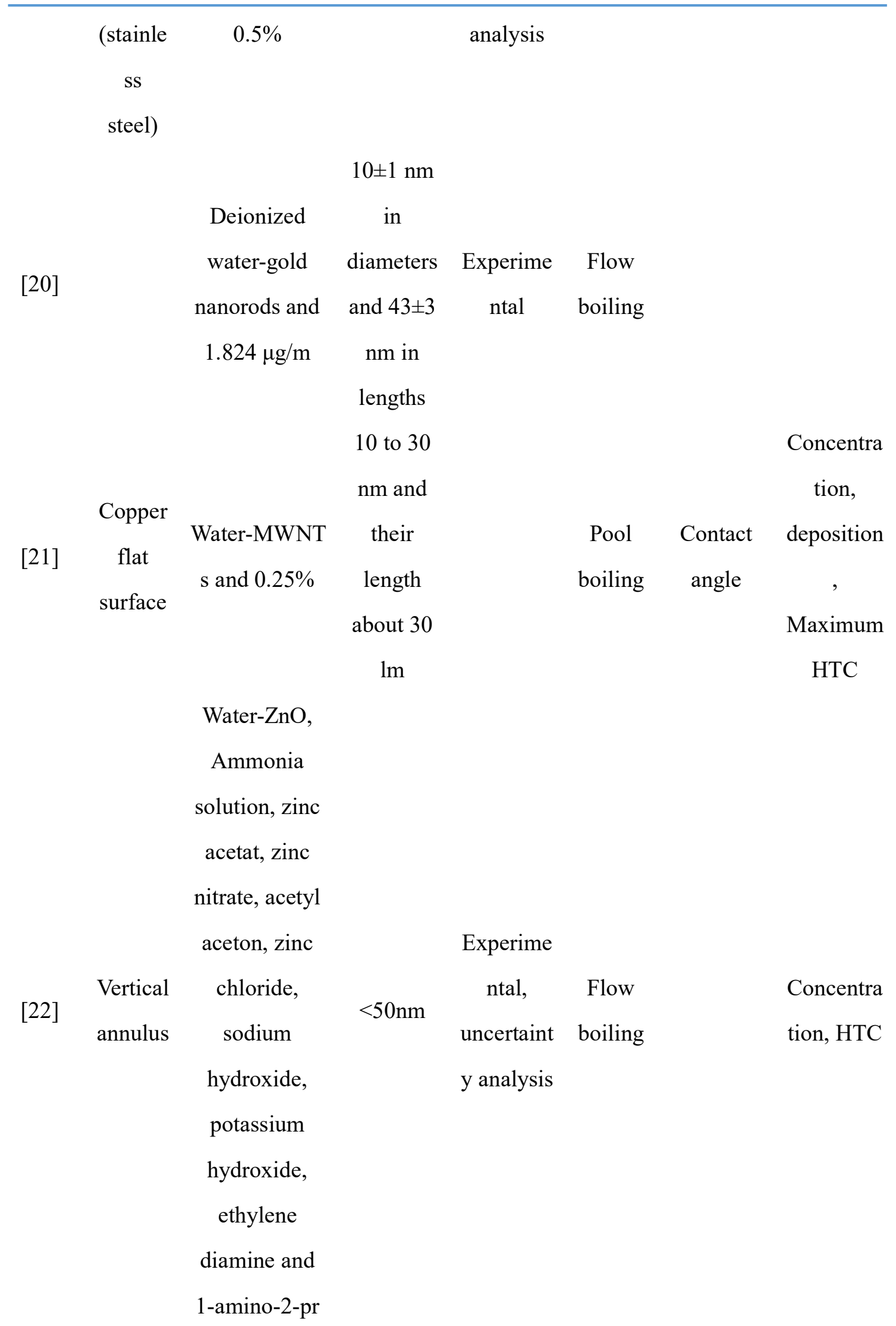


opanol and

0.005-0.02

vol\%

Water-alumin

a oxide and

$$
0.0 \text { wt. } \%
$$

(pure water),

$$
0.01 \text { wt.\% }
$$

[23]

[24]

Alumin

$$
\begin{aligned}
& \text { vol. } \%), 0.1 \quad 50 \mathrm{~nm} \\
& \text { wt. } \%(0.025 \\
& \text { vol. } \%) \text { and } \\
& 1.0 \text { wt. } \% \\
& (0.25 \text { vol. } \%) \text {. } \\
& 0.01 \text { wt. } \% \text { to } \\
& 1 \text { wt. } \% \text {. }
\end{aligned}
$$

\begin{tabular}{|c|c|c|c|}
\hline (SEM), & Pool & $\begin{array}{l}\text { Surface } \\
\text { roughness }\end{array}$ & Wettabilit \\
\hline $\begin{array}{l}\text { atomic } \\
\text { force }\end{array}$ & boiling & factor & $\mathrm{y}$ \\
\hline
\end{tabular}

$$
\begin{gathered}
\text { Scanning } \\
\text { electron } \\
\text { microsco } \\
\text { pe }
\end{gathered}
$$

$$
\text { py }
$$

(AFM)
Wall

superheat,

$$
\begin{array}{cc}
\text { Water- } \mathrm{TiO}_{2}, \mathrm{~A} & \\
\mathrm{l}_{2} \mathrm{O}_{3} \text { and } \mathrm{SiO}_{2} & 21(\mathrm{Ti}), \\
\text { and } 0.04,0.4 & 13(\mathrm{Al}), \\
\text { and } 1 \mathrm{~kg} / \mathrm{m}^{3} & 20(\mathrm{Si}) \mathrm{nm}
\end{array}
$$

$$
\begin{gathered}
\mathrm{ZnO} \\
\text { nanoparti }
\end{gathered}
$$

$\begin{array}{ccc}\text { Stainle } & \text { Pure } & \text { cle } \\ \text { ss steel } & \text { water- } \mathrm{ZnO}, & (10-30 \\ \text { surface } & \text { alumina oxide } & \mathrm{nm}), \\ & & \mathrm{Al}_{2} \mathrm{O}_{3}(80 \\ & & \mathrm{nm}),\end{array}$

Pool

boiling

CHF, concentrat ion particle

$\begin{array}{ccc}\text { Gorenflo } & & \text { Heat } \\ \text { correlatio } & \text { Boiling } & \text { transfer } \\ \mathrm{n} & & (\mathrm{ZnO}, \\ & & \text { alumina }) \\ & & \end{array}$

Heat transfer (CNT) 


\section{CNT}

nm OD

and

$10-30 \mathrm{~lm}$

length)

\section{CONCLUSION}

This paper summarized the extensive review of development of nanorefrigerant for enhancement of thermos-physical properties, especially on thermal conductivity. In early research on this field, researcher focus on mix the nanoparticle with water base. After, refrigerant base has a more potential in capability to enhance the thermos-physical properties. Many researchers begin to change their base fluids to refrigerant. The type of refrigerant based on chlorine contain from CFC group cause environmental effect already banned by Montreal Protocol. After, banned refrigerant issue, researcher begin to change on refrigerant base to alternative refrigerant that give a lot more minimum effect to environmental. Here author suggested to future researcher to experimental studies of nanorefrigerant using alternative refrigerant to minimize the environmental effect.

There a lot of factors of nanorefrigerant can cause enhancement or deterioration performance in thermal properties such as thermal conductivity, viscosity and etc. Here factor author can highlight from extensive review:

- Nanoparticle factor that can be effect to thermos-physical properties is nanoparticle size, type of nanoparticle, shape of nanoparticle size and etc. Thinner nanoparticle can be more effected to the base fluid thermos-physical properties.

- Refrigerant type need to be environmental friendly to minimized the Global Warming Potential (GWP) factor.

- The boiling temperature of refrigerant need to be aware of researcher to know how to handle in more the safest way handling and run experiment in easier method. The wasted of refrigerant also need to be included in selection of refrigerant to experiment studies because if the disposal way of refrigerant can make environmental effected. 
- The method of preparation for nanorefrigerant, there are many ways to prepare the nanofluids. There is 2 ways to homogenize nanoparticle from previous study, it is by using Shaker in controlled temperature and ultrasonic vibrator/bath/processor.

- The time of apply sonication also need considered by researcher, the time also can affect to thermal properties. Long-time sonication, does not mean better scattering of nanoparticle in refrigerant.

- The equipment of thermos-physical properties need to know the range of accuracy, usually refrigerant thermos-physical properties is low. The equipment need very low range of accuracy to give more accurate measurement of nanorefrigerant.

Last but not least, the theories in nanorefrigerant still in fundamental studies. More experimental studies can make easier to future researcher to understand of fundamental knowledge of nanorefrigerant.

\section{ACKNOWLEDGEMENTS}

The author would like to thank the Ministry of Higher Education Malaysia for the Graduate Research Assistant (GRA) scheme under FRGS no 600-RMI/FRGS 5/3 (68/2015) or sponsorship no. FRGS /1 /2015 / TK03/ UiTM/ 02/ 6.

\section{REFERENCES}

[1] Redhwan A A, Azmi W H, Sharif M Z, Mamat R.Development of nanorefrigerants for various types of refrigerant based: A comprehensive review on performance.International Communications in Heat and Mass Transfer, 2016, 76:285-293

[2] Diana A.Liquid-vapour phase change: Nucleate boiling of pure fluid and nanofluid under different gravity levels.Phd, thesis, Brisbane: Queensland University of Technology, 2013 [3] Mahbubul I M, Saidur R, Amalina M A.Influence of particle concentration and temperature on thermal conductivity and viscosity of $\mathrm{Al}_{2} \mathrm{O}_{3} / \mathrm{R} 141 \mathrm{~b}$ nanorefrigerant.International Communications in Heat and Mass Transfer, 2013, 43:100-104

[4] Tang X, Zhao Y H, Diao Y H. Experimental investigation of the nucleate pool boiling heat transfer characteristics of $\delta-\mathrm{Al}_{2} \mathrm{O}_{3}-\mathrm{R} 141 \mathrm{~b}$ nanofluids on a horizontal plate.Experimental Thermal and Fluid Science, 2014, 52:88-96 
[5] Mahbubul I M, Fadhilah S A, Saidur R, Leong K Y, Amalina M A. Thermophysical properties and heat transfer performance of $\mathrm{Al}_{2} \mathrm{O}_{3} / \mathrm{R}-134 \mathrm{a}$ nanorefrigerants.International Journal of Heat and Mass Transfer, 2013, 57(1):100-108

[6] Trisaksri V, Wongwises S.Nucleate pool boiling heat transfer of $\mathrm{TiO}_{2}-\mathrm{R} 141 \mathrm{~b}$ nanofluids.International Journal of Heat and Mass Transfer, 2009, 52(5-6):1582-1588

[7] Sun B, Yang D. Experimental study on the heat transfer characteristics of nanorefrigerants in an internal thread copper tube.International Journal of Heat and Mass Transfer, 2013, 64:559-566

[8] Naphon P, Thongkum D, Assadamongkol P. Heat pipe efficiency enhancement with refrigerant-nanoparticles mixtures.Energy Conversion and Management, 2009, 50(3):772-776

[9] Peng H, Ding G, Jiang W, Hu H, Gao Y. Measurement and correlation of frictional pressure drop of refrigerant-based nanofluid flow boiling inside a horizontal smooth tube.International Journal of Refrigeration, 2009, 32(7):1756-1764

[10] Peng H, Ding G, Jiang W, Hu H, Gao Y.Transfer characteristics of refrigerant-based nanofluid flow boiling inside a horizontal smooth tube.International Journal of Refrigeration, 2009, 32(6):1259-1270

[11] Jiang W, Ding G, Peng H. Measurement and model on thermal conductivities of carbon nanotube nanorefrigerants.International Journal of Thermal Sciences, 2009, 48(6):1108-1115 [12]Jiang W, Ding G, Peng H, Gao Y, Wang K.Experimental and model research on nanorefrigerant thermal conductivity.HVAC\&R Research, 2009, 15(3):651-669

[13]Peng H, Ding G, Hu H, Jiang W.Influence of carbon nanotubes on nucleate pool boiling heat transfer characteristics of refrigerant-oil mixture.International Journal of Thermal Sciences, 2010, 49(12):2428-2438

[14] Peng H, Ding G, Hu H, Jiang W, Zhuang D, Wang K. Nucleate pool boiling heat transfer characteristics of refrigerant/oil mixture with diamond nanoparticles.International Journal of Refrigeration, 2010, 33(2):347-358

[15]Sarafraz MM, Kiani T, Hormozi F. Critical heat flux and pool boiling heat transfer analysis of synthesized zirconia aqueous nano-fluids.International Communications in Heat and Mass Transfe, 2016, 70:75-83

[16] Soleimani B, Keshavarz A.Heat transfer enhancement of an internal subcooled flow 
boiling over a hot spot.Applied Thermal Engineering, 2016, 99:206-213

[17] Sayahi T, Tatar A, Bahrami M. A RBF model for predicting the pool boiling behavior of nano fluids over a horizontal rod heater.International Journal of Thermal Sciences, 2016, 99:180-194

[18]Wang Y, Deng K H, Liu B, Wu J M, Su G H. A correlation of nanofluid flow boiling heat transfer based on the experimental results of $\mathrm{AlN} / \mathrm{H}_{2} \mathrm{O}$ and $\mathrm{Al}_{2} \mathrm{O}_{3} / \mathrm{H}_{2} \mathrm{O}$ nanofluid. Experimental Thermal and Fluid Science, 2017, 80:376-383

[19] Wang Y, Su GH. Experimental investigation on nanofluid flow boiling heat transfer in a vertical tube under different pressure conditions.Experimental Thermal and Fluid Science, 2016, 77:116-123

[20] Wang Z, Quan X, Yao W, Wang L, Cheng P. Plasma resonance effects on bubble nucleation in flow boiling of a nano fluid irradiated by a pulsed laser beam.International Communications in Heat and Mass Transfer, 2016, 72:90-94

[21] Xing M, Yu J, Wang R. Effects of surface modification on the pool boiling heat transfer of MWNTs/water nanofluids.International Journal of Heat and Mass Transfer, 2016, 103:914-919

[22] Zangeneh A, Vatani A, Fakhroeian Z, Peyghambarzadeh S M.Experimental study of forced convection and subcooled flow boiling heat transfer in a vertical annulus using different novel functionalized $\mathrm{ZnO}$ nanoparticles.Applied Thermal Engineering, 2016, 109:789-802

[23]Zhang F, Jacobi A M. Aluminum surface wettability changes by pool boiling of nanofluids.Colloids and Surfaces A: Physicochemical and EngineeringAspects, 2016, $506: 438-444$

[24] Sulaiman M Z, Matsuo D, Enoki K, Okawa T.Systematic measurements of heat transfer characteristics in saturated pool boiling of water-based nanofluids.International Journal of Heat and Mass Transfer, 2016, 102:264-276

[25] Shoghl S N, Bahrami M, Jamialahmadi M. The boiling performance of $\mathrm{ZnO}, \alpha-\mathrm{Al}_{2} \mathrm{O}_{3}$ and MWCNTs/water nanofluids: An experimental study.Experimental Thermal and Fluid Science, $2017,80: 27-39$ 
How to cite this article:

Rehim M Z A, Nawi M R M. Recent progress of nanorefrigerant development: a review. J. Fundam. Appl. Sci., 2017, 9(5S), 277-294. 